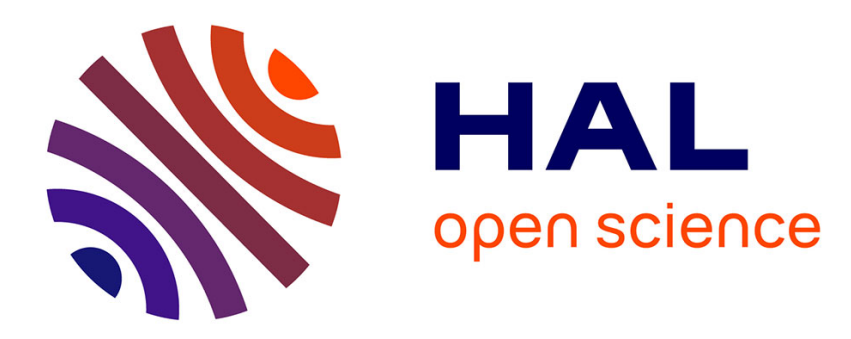

\title{
Analyses of Void Growth and Coalescence in Cast Iron by Cell Models
}

\author{
M. Kuna, D.-Z. Sun
}

\section{To cite this version:}

M. Kuna, D.-Z. Sun. Analyses of Void Growth and Coalescence in Cast Iron by Cell Models. Journal de Physique IV Proceedings, 1996, 06 (C6), pp.C6-113-C6-122. 10.1051/jp4:1996611 . jpa-00254439

\section{HAL Id: jpa-00254439 https://hal.science/jpa-00254439}

Submitted on 1 Jan 1996

HAL is a multi-disciplinary open access archive for the deposit and dissemination of scientific research documents, whether they are published or not. The documents may come from teaching and research institutions in France or abroad, or from public or private research centers.
L'archive ouverte pluridisciplinaire HAL, est destinée au dépôt et à la diffusion de documents scientifiques de niveau recherche, publiés ou non, émanant des établissements d'enseignement et de recherche français ou étrangers, des laboratoires publics ou privés. 


\title{
Analyses of Void Growth and Coalescence in Cast Iron by Cell Models
}

\author{
M. Kuna and D.-Z. Sun \\ Fraunhofer-Institute of Mechanics of Materials, Wöhlerstrasse 11, 79108 Freiburg, Germany
}

\begin{abstract}
The fracture process of cast iron is initiated at the graphite nodules, followed by intensive void growth and coalescence. Two- and three-dimensional cell models are developed to study the influence of stress triaxiality and void arrangement on these microscopical damage processes in nodular cast iron. The applicability of the Gurson model to this type of material is investigated and related to the cell model results. The calculations show that during a tensile loading graphite nodules hinder the transverse deformation of the matrix if the stress triaxiality for the loading is less than $\sigma_{\mathrm{b}} / \sigma_{\mathrm{c}}=0.5$. Otherwise the graphite nodules can simply be modelled by voids. The three-dimensional cell models turned out that the spatial arrangement of periodic arrays of voids has only weak influence on the deformation behaviour, whereas the plastic collapse behaviour is strongly affected. The simulation of tensile tests with notched bars demonstrates that the Gurson model can be used to characterize nodular cast iron if the triaxiality of the loading is not too low.
\end{abstract}

\section{INTRODUCTION}

The usage of nodular cast iron in power plant technology requires the assessment of its failure behaviour, see e.g. [1]. The fracture behaviour of nodular cast iron depends strongly on the graphite morphology, i.e. the size, shape and distribution of the graphite nodules. In contrast to steel, void nucleation occurs in cast iron at very low loading due to the weak binding between the matrix and the nodules. Therefore, fracture processes in nodular cast iron are controlled by the subsequent phases of void growth and coalescence. Because of the large content of graphite the initial void volume fraction is higher than $10 \%$. Micromechanical damage models, as for example the modified Gurson model $[2,3]$, are based on the description of the relevant damage processes in the microstructure of the material. That's why it can be expected that they have the potential to relate the flow properties and the fracture toughness of nodular cast iron to its microstructure. However, before their application two questions have to be answered. At first, can the nodules be treated as voids for the whole loading process? Secondly, can models of the Gurson-type be successfully applied to materials with such high initial porosity, where the interaction of voids can not be neglected ? The present paper is concerned with the above mentioned questions. Furthermore, special emphasis is drawn to the influence of the kind of spatial arrangements of void arrays on the mesoscopic deformation behaviour and on the constitutive softening, which is expected to be more pronounced for this high porosity. The numerical details of this extensive parameter study are reported in [13]. In order to make the observed three-dimensional effects available to structural analysis, attempts were made to calibrate the parameters of the Gurson-Tvergaard model by the cell model results. 


\section{THE MODIFIED GURSON MODEL}

Gurson [2] derived a constitutive law for a plastic matrix containing spherical voids from an approximative plastic flow potential $\Phi$, whereby the average porosity $f$ and the actual flow stress $\sigma=H\left(\varepsilon_{p}\right)$ of the matrix serve as state variables. $\Sigma_{i j}$ means the mesoscopical stress tensor. This model was modified by Tvergaard and Needleman [3], who introduced the parameters $q_{1}, q_{2}$ (which are usually set to 1.5 and 1.0) and $f^{*}$ to account for the void interaction and for an accelerated void coalescence above $f>f_{c}$, respectively.

$$
\phi\left(\Sigma_{i j}, f, \sigma\right)=\frac{3 \Sigma_{i j}^{\prime} \Sigma_{i j}^{\prime}}{2 \sigma^{2}}+2 q_{1} f^{*} \cosh \left(\frac{q_{2} \Sigma_{k k}}{2 \sigma}\right)-1-\left(q_{1} f^{*}\right)^{2}=0
$$

The process of void coalescence starts, when the void volume fraction $f$ exceeds the critical value $f_{c}$. If $f$ reaches the ultimate value of $f_{f}$ or $f^{*}{ }_{u}=1 / q_{1}$, then the material loses its load-carrying capacity.

$$
f^{*}= \begin{cases}f & \text { for } f \leq f_{c} \\ f_{c}+\frac{f_{u}^{*}-f_{c}}{f_{f}-f_{c}} \cdot\left(f-f_{c}\right) & \text { for } f \geq f_{c}\end{cases}
$$

The evolution equation for the void volume fraction consists of a term for nucleation of new voids $f_{\text {nucl }}$ and a contribution resulting from void growth $f_{\text {growth }}$, which is related to the plastic volume change.

$$
\dot{f}=\dot{f}_{\text {nucl }}+\dot{f}_{\text {growth }} \quad \dot{f}_{\text {growth }}=(I-f) \dot{E}_{k k}^{p}
$$

More information about the actual developments of this model can be found in the review [12]. The GursonTvergaard model was implemented as user supplied material subroutine into ABAQUS and applied successfully to ductile fracture predictions in ferritic steels by Sun et al [4].

For cast iron the initial void volume fraction was set equal to the content of graphite, i.e. $f_{0}=0.114$. This means, that an immediate decohesion at all nodules is implied. The nucleation of new voids in the matrix during loading was neglected, therefore $f_{n u c l}$ was set to zero. The true stress versus true strain curve $\sigma=H\left(\varepsilon_{p}\right)$ of the pure matrix-like material (ferritic Fe, Si) of the cast iron was measured from a special metallurgical heat with no graphite content [5]. It was input in the finite element analyses in a pointwise manner. The initial yield stress, the elastic modulus and Poisson's ratio amounted to $\sigma_{o}=366.0 \mathrm{MPa}, E=195000.0 \mathrm{MPa}$ and $v=0.3$, respectively. There remain three parameters to be determined, namely: $f_{c}, f_{f}$ and $q_{1}$. Their specific values can be obtained either from cell model computations as it was done in $[5,7,8,12]$ or/and from numerical simulations of tensile tests $[4,6]$. Both approaches will be pursued in this paper and explained below.

\section{CELL MODEL ANALYSES}

Because analytical methods can only provide constitutive damage laws under simplified assumptions (i.e. isolated voids, ideal plastic matrix , unchangeable spherical shape of voids etc.), the numerical simulation of detailed microstructural phenomena by means of cell models offers further progress, see [12]. Koplic and Needleman [7], Brocks et al [8] carried out axisymmetrical finite element computations of cylindrical unit cells containing a spherical void under various triaxial loading conditions. However, such cylindrical unit cells do not allow the adjustment of arbitrary stress ratios in three directions. Furthermore, an assembledge of these cells cannot fill the space continuously, i.e. the approximation is suited only for moderate porosity. Threedimensional cell models were first published by McMeeking and Hom [9], Worswick and Pick [10] and Richelsen and Tvergaard [11,12]. In all papers a cubic periodical array of initially spherical voids was presumed with small porosities typical for steel. Two-dimensional and axisymmetrical cell model computations for nodular cast iron were reported in $[5,6]$. 


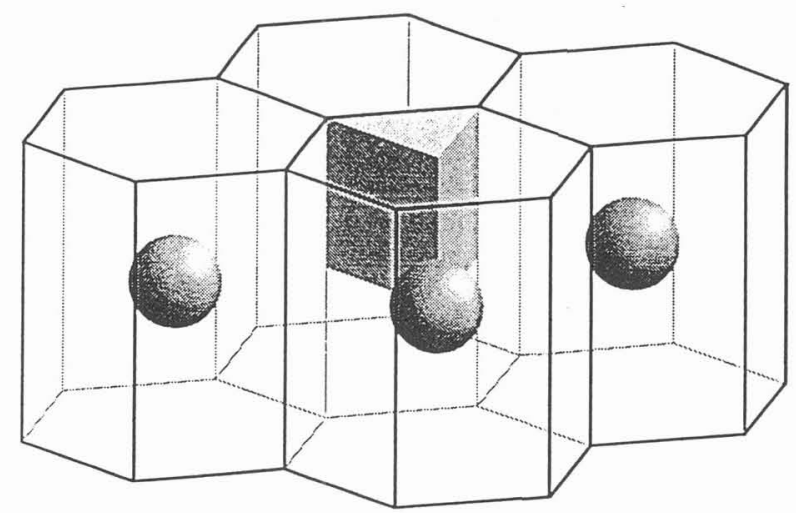

Fig. 1: Three-dimensional hexagonal arrangement of voids

\subsection{Spatial arrangements of voids and representative unit cells}

\subsubsection{Hexagonal void arrangement with axisymmetrical unit cells}

The positions of voids are assumed to form a hexagonal crystal lattice as shown in Fig. 1. The unit cells have the form of a prism with hexagonal basis face (inner radius $=\mathrm{L}$ ) and height $2 \mathrm{~L}$. In order to reduce the effort of analysis to a two-dimensional problem, the cross section of the unit cell was simplified as a cylinder, as done in $[7,8]$. The used 2D finite element mesh with 480 elements is shown in Fig. 2.
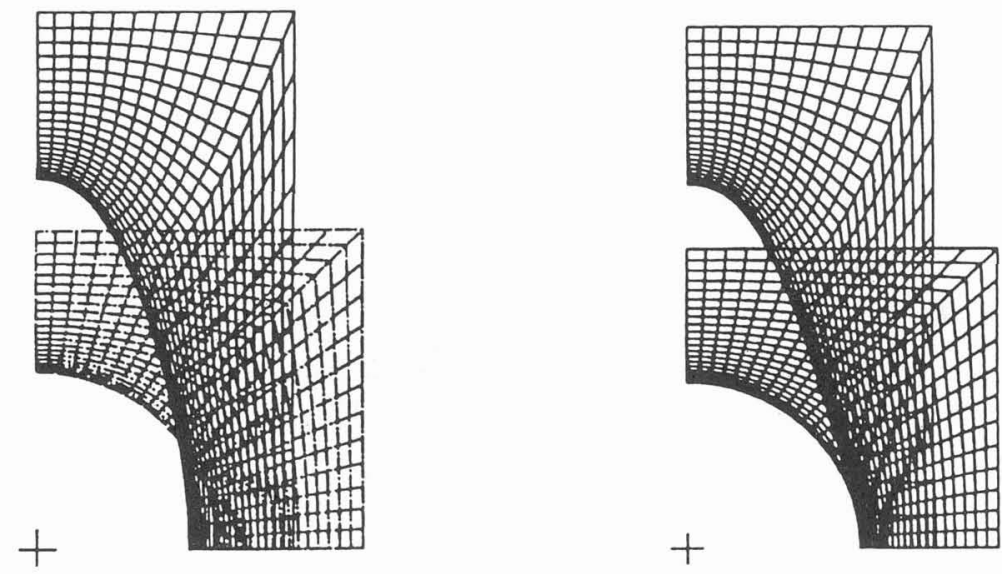

Fig. 2: Axisymmetrical finite element meshes for the hexagonal void arrangement.

Undeformed and deformed meshes with void (left) or rigid graphite inclusion (right)

\subsubsection{Hexagonal void arrangement with $3 D$ unit cells}

Here the unit cells of Fig. 1 are modelled with their proper hexagonal form. Because of symmetry and periodicity the cell can be subdivided into 12 equal triangular prisms as illustrated in Fig. 1, each of which 
possesses again one symmetry plane. Thus, only $1 / 24$ part of the cell has to be considered using appropriate boundary conditions, provided the applied stresses in the basic plane are assumed to be equal $\left(\Sigma_{11}=\Sigma_{22} \neq \Sigma_{33}\right)$, i.e. an axisymmetrical stress state is produced. The finite element mesh for the 1/24 geometry is depicted in Fig. 3 consisting of 360 elements and 9771 degrees of freedom.

\subsubsection{Cubic primitive void arrangement with $3 D$ unit cells}

This is the most simple 3D structure [9-11]. The unit cell consists of a cube with initial edge lengths of $2 L_{o} \times 2 L_{o}$ $x 2 L_{o}$ containing a hole of initial radius $R_{o}$ placed in the centre. Due to the three-fold symmetry only $1 / 8$ of the cell has to be discretized.

\subsubsection{Body centred cubic void arrangement with $3 D$ unit cells}

This arrangement exhibits the most dense packaging of voids. Due to the diagonal orientation of the voids to each other another plastic collapse mechanism was expected to occur. The loading was again directed parallel to the lattice axes with different amplitudes. For the sake of brevity, models 3.1.3 and 3.1.4 are not depicted here, but results will be included in Fig. 8. Readers are referred to [13].

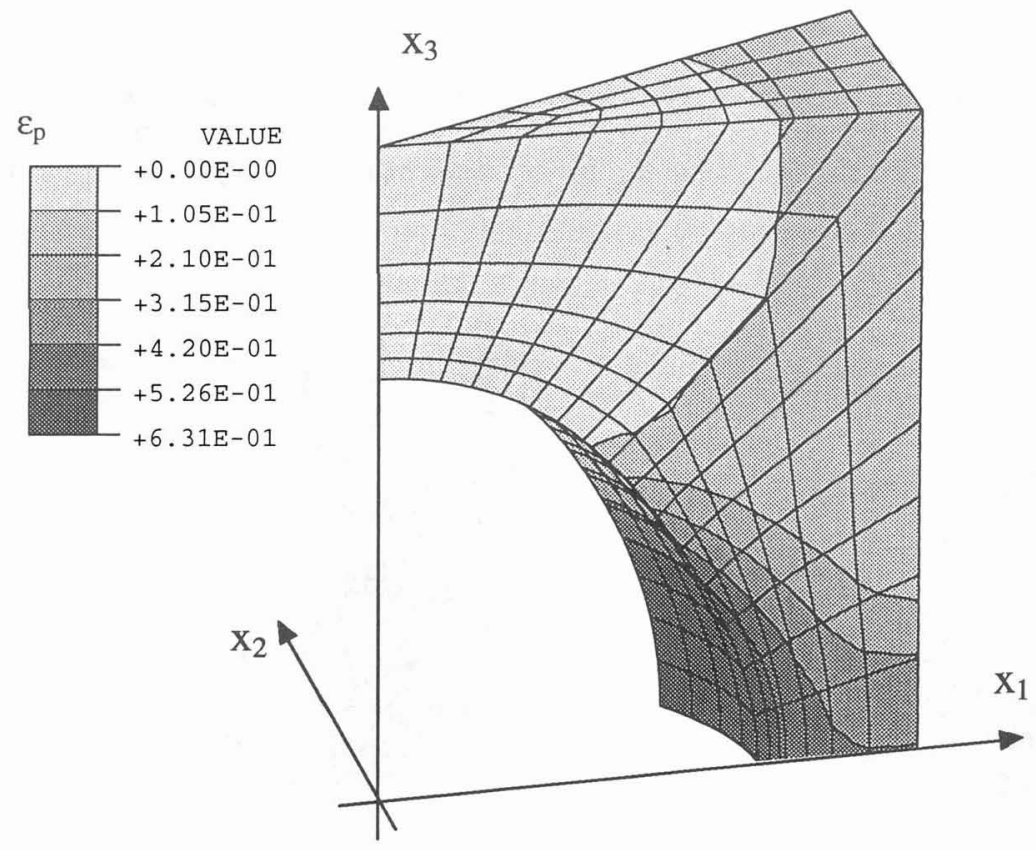

Fig. 3.

Deformed finite element model of the prismatic unit cell for a hexagonal void arrangement.

Fringe plots of equivalent plastic strain for triaxiality $\mathrm{T}=1.0$ at maximum load level

The initial void volume fraction $f_{o}=0.114$ must be equivalent to the ratio of void volume and the total cell volume prior deformation. The resulting void radii $R_{o}$ can be obtained by simple geometric relations and were summarized for the considered four types of unit cells:

$$
\begin{array}{rlrlr}
\frac{R_{o}}{L} & =\left\{\sqrt[3]{\frac{3 f_{o}}{2}} ;\right. & \sqrt[3]{\frac{9 f_{o}}{\pi \sqrt{3}}} ; & \sqrt[3]{\frac{6 f_{o}}{\pi}} ; & \left.\sqrt[3]{\frac{3 f_{o}}{\pi}}\right\} \\
& =\{0.5550 ; & 0.5734 ; & 0.6016 ; & 0.4775\} \\
& \text { hexagonal axi } & \text { hexagonal 3D } & \text { cubic primitive } & \text { cubic body centered }
\end{array}
$$




\subsection{The mechanical modelling of unit cells}

In the analysis a multiaxial loading of the void arrangements in directions parallel to the axes of periodicity was considered, i.e. the global coordinate system $x_{i}$. Thus, the principal directions of the applied mesoscopic stresses $\Sigma_{i j}$ and the resulting deformations $E_{i j}$ coincide with each other and the coordinate axes (principal values are denoted by $\left.\Sigma_{i}, E_{i}, \quad i=1,2,3\right)$. All outer planes of the unit cells have the kinematic restriction to move as rigid planes with uniform normal displacements $U_{i}(i=1,2,3)$ in coordinate directions. This is a consequence of the lattice periodicity. The mutual orientations between the faces of the unit cells remain fixed during deformation. This feature was imposed by multi-point-constraints, see [14].The inner planes of symmetry of the cell models will be fixed against normal displacements. For the hexagonal cell model (Fig. 3 ) the symmetry holds for the bottom plane $\left(U_{3}=0\right.$ at face $\left.x_{3}=0\right)$ and the front plane $\left(U_{2}=0\right.$ at face $\left.x_{2}=0\right)$, whereas on the oblique plane of the wedge the normal displacements were suppressed by corresponding multi-point-constraints.

The applied mesoscopic stress state is characterized by its triaxiality ratio $T=\Sigma_{h} / \Sigma_{0}$ between the hydrostatic component $\Sigma_{h}$ and the v. Mises effective stress $\Sigma_{e}$.

$$
\Sigma_{h}=\frac{1}{3}\left(\Sigma_{1}+\Sigma_{2}+\Sigma_{3}\right) ; \quad \Sigma_{e}=\left[\frac{1}{2}\left(\Sigma_{3}-\Sigma_{1}\right)^{2}+\frac{1}{2}\left(\Sigma_{2}-\Sigma_{3}\right)^{2}+\frac{1}{2}\left(\Sigma_{1}-\Sigma_{2}\right)^{2}\right]^{1 / 2}
$$

The triaxiality varies from $T=0$ for pure shear, over $T=1 / 3$ for uniaxial tension up to values of about $T=3.0$ at notches and crack tips. In most cases, we adjusted the presumed triaxiality by setting $\Sigma_{3}=1$ and by choosing the lateral stresses $\Sigma_{l}=\Sigma_{2}=\alpha \Sigma_{3}$, with the factor $\alpha=(3 \mathrm{~T}-1) /(3 \mathrm{~T}-2)$. In order to keep the triaxiality of the mesoscopic stress state constant in the course of loading irrespective of the appearing large deformations of the cell faces and unstable stiffness behaviour, the RIKS-option in ABAQUS [14] was used successfully [13].The large strain finite element calculations were performed using ABAQUS. For the material inside of the unit cells isotropic v. Mises plasticity was presumed, using the above mentioned pure matrix-like properties of cast iron.

The overall mesoscopic strain rates in the principal directions of the unit cells can be calculated from the normal displacements $U_{i}$ of the outer faces and have to be integrated along the loading history [13]:

$$
\begin{aligned}
\dot{E}_{i} & =\left(\frac{\dot{L}_{i}}{L_{i o}}\right)=\left(1+\frac{\dot{U}_{i}}{L_{i o}}\right) & E_{i} & =\ln \left(1+\frac{U_{i}}{L_{i o}}\right) \\
E_{e} & =\int \dot{E}_{e} d t & \dot{E}_{e} & =\frac{2}{3}\left[\frac{1}{2}\left(\dot{E}_{3}-\dot{E}_{1}\right)^{2}+\frac{1}{2}\left(\dot{E}_{2}-\dot{E}_{3}\right)^{2}+\frac{1}{2}\left(\dot{E}_{1}-\dot{E}_{2}\right)^{2}\right]^{1 / 2}
\end{aligned}
$$

The actual void volume fraction $f$ can be computed from the deformations of the unit cells via the condition of plastic incompressibility, i.e. the volume of the pure matrix material has to remain constant, [7]:

$$
f=I-\frac{V_{0}}{V}\left(I-f_{0}\right)-\frac{\Delta V_{e}}{V} \quad \Delta V_{e}=V_{0}\left(I-f_{0}\right) \frac{3(1-2 v)}{E} \Sigma_{h}
$$

Here, $V_{o}$ is the volume of the undeformed cell, and $\Delta V_{e}$ is an approximate correction term (see $[9,10]$ ) for the elastic dilatational change in cell volume due to the imposed hydrostatic stress $\Sigma_{h}$. The current volume $V$ of the rectangular unit cells is easily obtained from their actual outer displacements $U_{i}$.

\subsection{Results}

Computations were carried out for all four cell models, whereby the extreme values of stress triaxiality $T=1 / 3$, 1.0 and 3.0 were investigated [13]. The most interesting outcome from the cell models is the overall mesoscopic 
hardening and failure behaviour. This relation is expressed in terms of the invariants of $J_{2}$-plasticity, i.e. the equivalent stress $\Sigma_{\boldsymbol{e}}$ versus equivalent strain $\mathrm{E}_{\mathrm{o}}$.
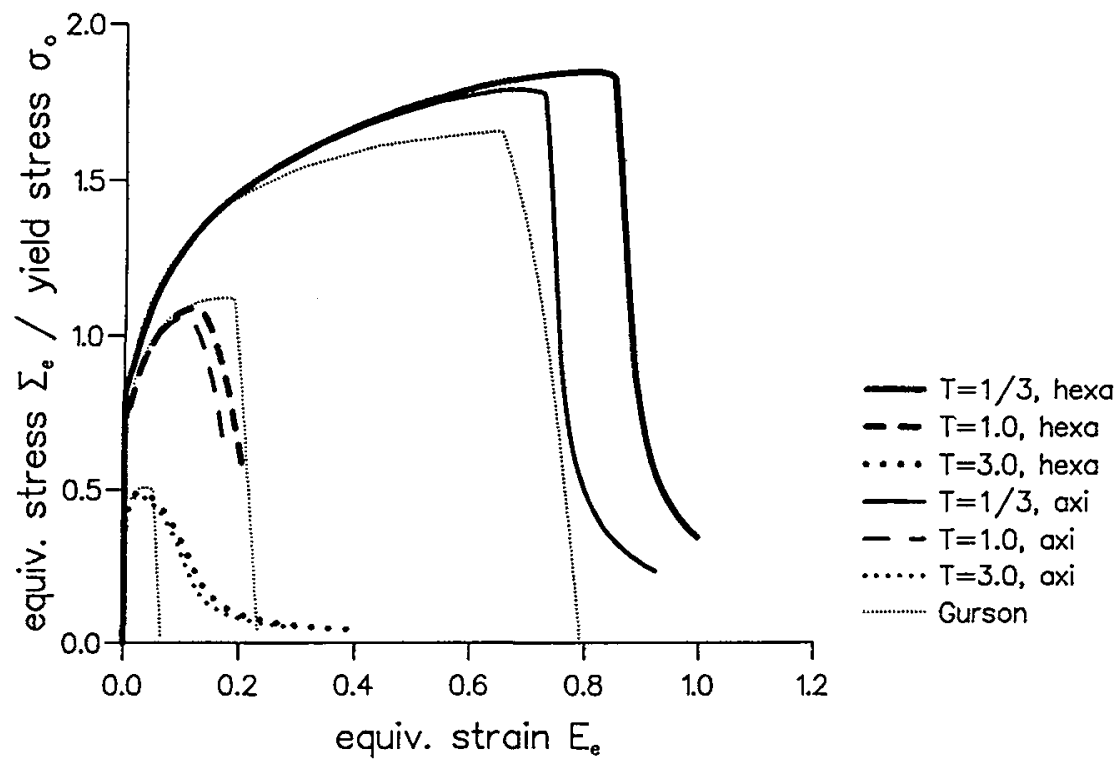

Fig. 4a: Results of hexagonal cell models for varying stress triaxiality

a) equivalent stress versus equivalent strain

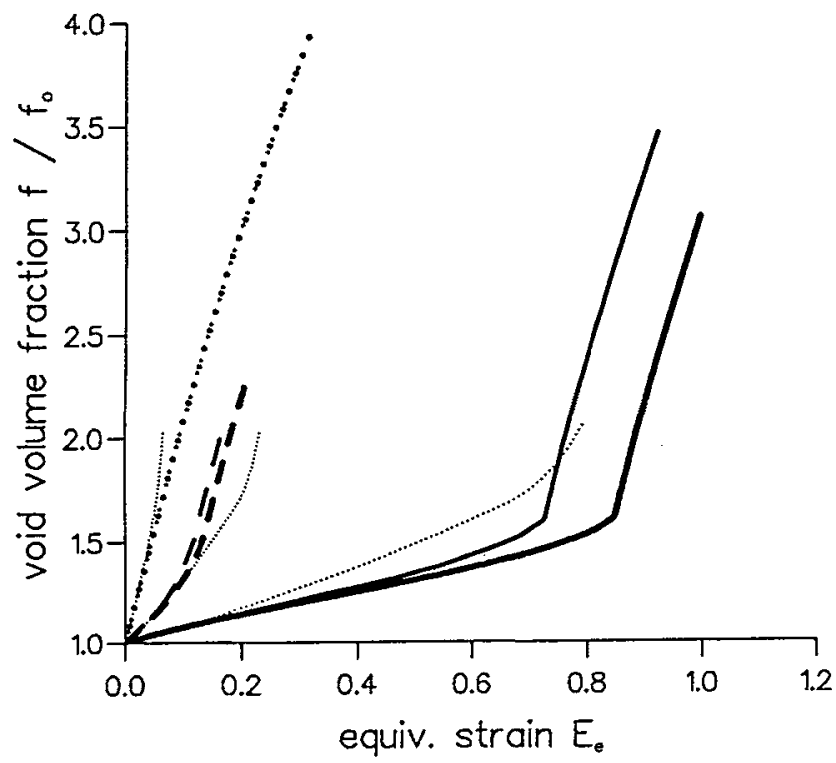

$$
\begin{aligned}
& -T=1 / 3, \text { hexa } \\
& -T=1.0, \text { hexa } \\
& \ldots . T=3.0, \text { hexa } \\
& -T=1 / 3 \text {, axi } \\
& -T=1.0, \text { axi } \\
& \ldots \ldots T=3.0, \text { axi } \\
& \ldots . . . . . \text { Gurson }
\end{aligned}
$$

Fig. 4b: Results of hexagonal cell models for varying stress triaxiality

b) void volume fraction versus equivalent strain

The obtained results for the axisymmetrical and 3D hexagonal arrangement are presented in Fig. 4a and 4b. In the course of loading, the plastic deformation is localized at the circumference of the void (Fig. 3), leading to further plastification and necking of the whole cross section. When the geometrical softening of the unit cell 
could not be compensated by the hardening of the matrix material, the maximum load value was reached and the plastic collapse of the unit cell proceeded rapidly. The higher the stress triaxiality is, the earlier and lower is the attained collapse load. This is caused by strong influence of stress triaxiality on void growth, which can be observed also from Fig. 4b. Comparing the results of the axisymmetrical cell models with the 3D ones, it turned out that the deformation behaviour agrees well with 3D analyses, but the onset of failure and accelerated void growth occurs noticeable earlier. That means, the frequently used axisymmetrical cell models [5-8] deliver a lower collapse strength.
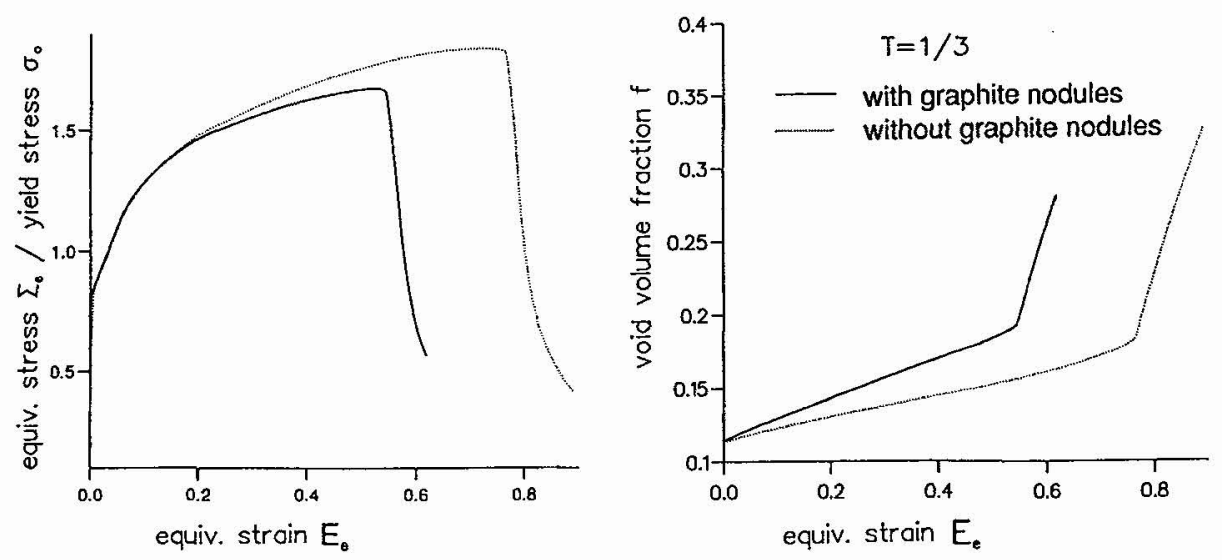

Fig. 5: Results of axisymmetrical cell model with and without graphite inclusions

a) equivalent stress and $b$ ) void volume fraction as function of equivalent strain
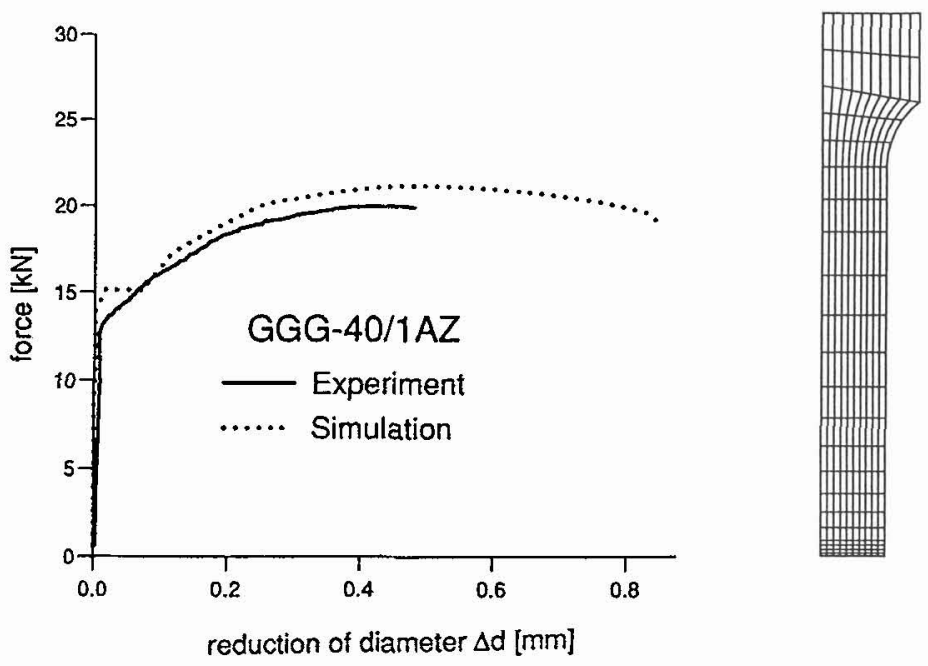

Fig. 6: Simulation of the smooth tensile bar. Axial force versus lateral necking

Following a procedure proposed by Aravas and McMeeking (see e.g. [7, 8, 13]), the modified Gurson model can be numerically integrated for axisymmetrical proportional loading. This yields the equivalent stress $\Sigma_{e}$ and the void volume fraction $f$ as function of the equivalent plastic strain $E_{e}$. By means of this technique, the free parameters $f_{c}, f_{f}$, and $q_{1}$ were varied in a suitable manner to find the best fit with respect to a given complete set 
of finite element cell model results. The best Gurson approximation of the cell model results are compiled in Table 1. The calibration (set \#4) for the 3D hexagonal cells is included in Fig. 4a and 4b. A Gurson-fit of the axisymmetrical results provided the parameter set \#5, which fully agrees with the result reported in [5].

To study the influence of the graphite nodules on the cell behaviour, two different finite element models were generated for the axisymmetrical computations. In the first model, the nodules were approximated by holes, as done in all previous cases. In the other one, the nodules were simulated as rigid spherical inclusions but without cohesion to the matrix. Fig. 2 shows the deformations of both models at equal loading for a stress triaxiality of $T=1 / 3$. It can be seen that in the first model the elongated void is contracted in lateral direction, which in reality is nearly impossible due to the stiffness of the included nodules. This phenomenon was correctly reflected by the second model. The model with nodules gives a weaker hardening but stronger development of porosity, Fig. 5 . Further studies revealed that for triaxialities higher than $\mathrm{T}=0.5$ no lateral contraction takes place anymore.

\section{SIMULATION OF TENSILE TEST SPECIMENS}

Smooth and notched tensile tests on nodular cast iron were carried out in [5]. The specimens had a diameter of $8 \mathrm{~mm}$ and length of about $40 \mathrm{~mm}$. The notch radius was $4 \mathrm{~mm}$. The geometries can be seen from the corresponding finite element meshes depicted in Fig. 6 and 7. These experiments were numerically simulated by means of the modified Gurson law. The following set of Gurson parameters was selected, which was capable to reproduce the experimental findings best: $f_{o}=0.114, f_{c}=0.13, f_{f}=0.272$ and $q_{t}=1.43$.
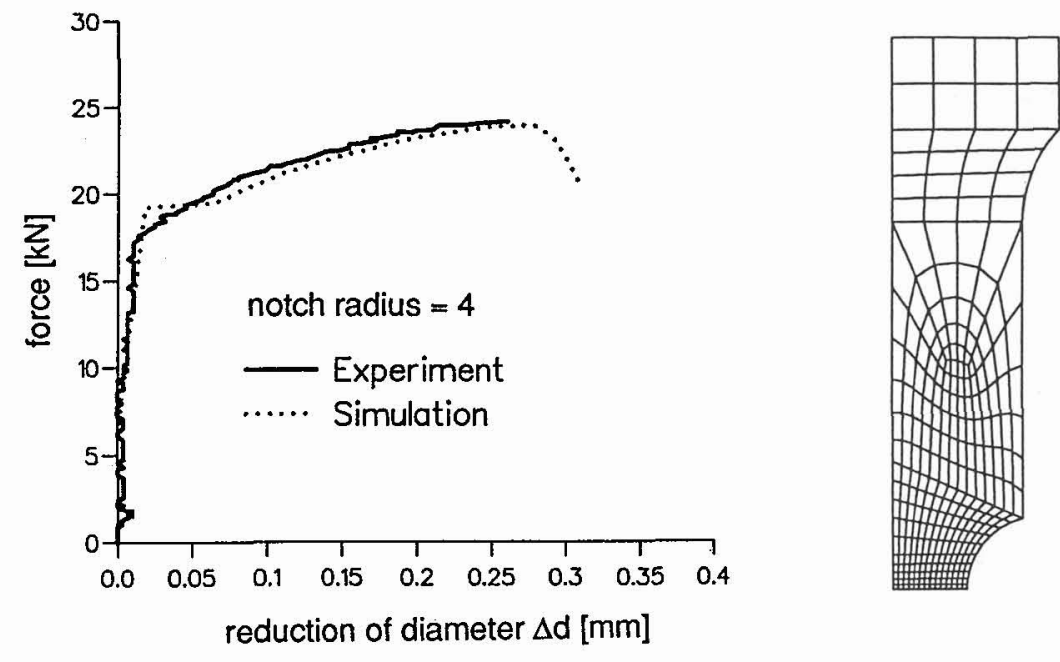

Fig. 7: Simulation of the notched tensile bar. Axial force versus lateral necking

The finite element analysis of the smooth tensile bar turned out that the longitudinal deformation met the experimental results well, however the necking behaviour of the cross section was overestimated by the simulation, see Fig. 6. The reason is the inherent assumption of voids in the Gurson model, whereas the above cell model calculations have elucidated the lateral stiffening effect of the graphite nodules for this triaxiality. On the other hand, the simulation of the notched specimens with the same parameter set fits the experimental results very well, Fig. 7. Because the level of triaxiality in the notched specimens is larger than $T=0.5$ across the whole notch region, it becomes clear, why the stiffening influence of the nodules does not operate in that case. 


\section{DISCUSSION AND CONCLUSIONS}

The results of the different 3D cell models from chapter 3 were assembled in Fig. 8. The effect of the spatial void arrangements can be classified in the following sequence:

I. hexagonal arrangement (approximate 2D-axisymmetrical unit cell)

II. hexagonal arrangement (3D unit cell)

III. cubic primitive arrangement (3D unit cell)

IV. cubic body centred arrangement (3D unit cell)

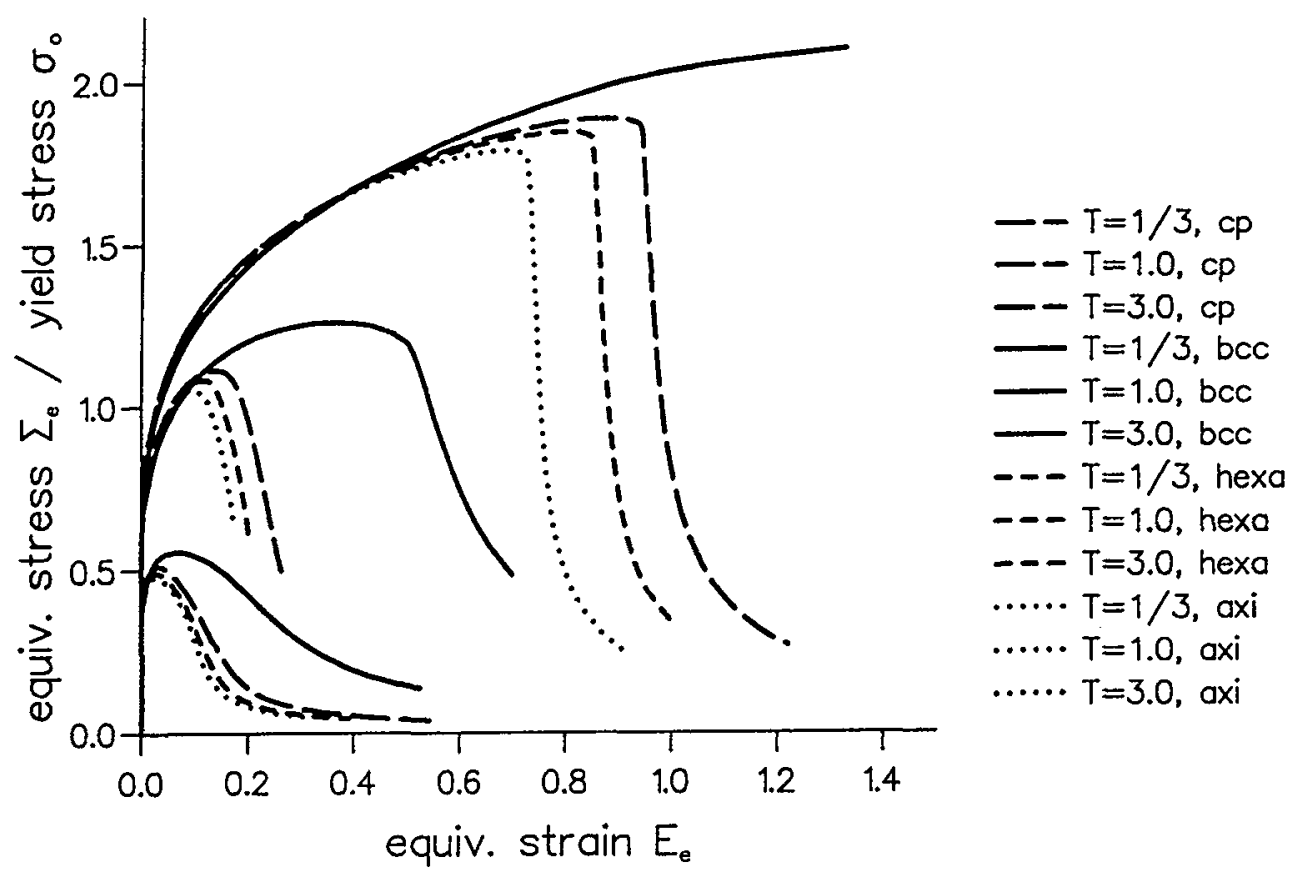

Fig. 8: Comparison of equivalent stress versus equivalent strain for all spatial cell models (varying stress triaxiality)

With ascending order the cell models exhibit an increasing hardening, a higher collapse load at higher strains and a decreasing evolution of void volume fraction. The type of void arrangement affects only weakly the deformation behaviour, whereas the maximum load and plastic collapse mechanism are strongly influenced. Another important outcome is that the value of $f_{c}$ characterizing the beginning of void coalescence, seems to be quite independent of the value of triaxiality in all models, see Fig. 4.

It could be shown that axisymmetrical cell models yield a softer deformation behaviour and a lower failure stress than all 3D cell models. This means, the frequently used axisymmetrical cell models can only be regarded as upper bounds concerning the assessment of failure by ductile damage.

An application of the Gurson model to nodular cast iron is justified, if the stress triaxiality is above $T=0.5$. Otherwise the lateral contractions are overestimated, because the porosity model can not correctly reflect the stiffening effect of the graphite nodules. This explains, why the Gurson model is not able to predict smooth tensile bar experiments properly in cast iron.

The choice of the most suitable Gurson model parameters encountered the following situation, demanding further research: Those parameter sets, calibrated from cell model computations, do not best of all met the 
requirements for an exact simulation of tensile tests. All parameter sets extracted from cell models (given in Table 1) would result in a stronger hardening behaviour if used for tensile test simulations. This must be caused by additional softening mechanisms (like e.g. shear banding), which are up to now not involved in the cell model analyses.

Table 1: Summary of parameter sets to calibrate the Gurson model

\begin{tabular}{l|lllll}
\hline & cell model & $f_{o}$ & $f_{c}$ & $f_{f}$ & $q_{1}$ \\
\hline$\# 1$ & cubic primitive & 0.114 & 0.2 & 0.35 & 1.1 \\
$\# 2$ & cubic bcc & 0.114 & 0.3 & 0.44 & 1.1 \\
$\# 4$ & hexagonal & 0.114 & 0.19 & 0.235 & 1.2 \\
$\# 5$ & axisymmetrical & 0.114 & 0.175 & 0.235 & 1.2 \\
\hline
\end{tabular}

\section{References}

[1] Berger, Ch., Wiemann, W. Bruchmechanische Eigenschaften in dickwandigen Gußstücken aus Gußeisen mit Kugelgraphit als Kriterium für die Konstruktion, VDI-Bericht 469 (1988), 47-58

[2] A. L. Gurson, Journal of Engineering Materials \& Technology 99 (1977), 2-15

[3] Tvergaard, V. Needleman, A. Acta Metallurgica 32 (1984) 157-169

[4] D. Z. Sun, R. Kienzler, B. Voss, and W. Schmitt Application of micro-mechanical models to the prediction of ductile fracture", Fracture Mechanics: Twenty-Second Symposium (Volume II), ASTM STP 1131, eds. S. N. Atluri, J. C. Newman, Jr., I. S. Raju, and J.S. Epstein, American Society for Testing and Materials, Philadelphia, 1992, 368-378.

[5] W. Brocks, G. Pusch, W. Baer, D. Steglich (1995) DFG-Report: "Anwendung mikromechanischer Modelle der Werkstoffschädigung zur gefügeabhängigen Bewertung der Zähigkeit von duktilen Gußeisenwerkstoffen"

[6] D.Z. Sun .."Mikromechanische Simulation des Verformungs- und Bruchverhaltens von Gußeisenwerkstoffen", IWM-Report T25/1995

[7] Koplic, J. and Needleman, A. International Journal of Solids and Structures 24 (1988), 835-853.

[8] W. Brocks, D.Z. Sun and A. Hönig, International Journal of Plasticity 11 (1995) 971-989

[9] R.M. McMeeking and C. L. Hom, International Journal of Fracture 42 (1990) 1-19

[10] M.J. Worswick and R.J. Pick, Journal Mechanics and Physics of Solids 38 (1990) 601-625

[11] A. B. Richelsen and V. Tvergaard, Acta Metallurgica 42 (1994) 2561-2577

[12] Tvergaard, V. Micromechanics of damage in metals, in: Mechanical Behaviour of Materials (ed. A. Bakker) Delft University Press, Delft, The Netherlands, pp. 23-43

[13] Kuna, M., D.Z.Sun, Three-dimensional cell model analyses of void growth in ductile materials International Journal of Fracture (1996), submitted for publication

[14] ABAQUS Theory Manual Version 5.4, Hibbitt, Karlsson \& Sorensen Inc. 1994, 